\title{
Analysis of Topologic Properties and Road Structure of Tangshan Bus Traffic Network
}

\author{
Yue Zhang $^{1 *}$, Dengsui Wang ${ }^{2}$, Ziheng Zhang ${ }^{3}$ \\ ${ }^{1}$ College of Electrical Engineering, North China University of Science and Technology, Tangshan, \\ China \\ ${ }^{2}$ Yisheng College, North China University of Science and Technology, Tangshan, China \\ ${ }^{3}$ Institute of Electrical Engineering, Yanshan University, Qinhuangdao, China \\ *Corresponding Author.
}

\begin{abstract}
Tangshan is a city rebuilt after the earthquake. The urban construction was replanned, which directly designed the road structure. Therefore, this paper analyzes Tangshan bus network from two aspects of topologic properties and road structure. After analyzing the data of Tangshan bus network, this paper proposes an analysis method based on complex network theory for Tangshan bus network. This paper first established Tangshan bus line Space-L network model, and obtained node degree, node strength, bearing pressure, and clustering coefficient in the model. And then established transfer Space-P network model, with topologic properties, such as node degree, average distance, closeness centrality and betweenness centrality obtained. In order to distinguish different districts precisely, the bus stops in different districts are marked with different colors in Tangshan bus model figure. Finally, spatial bus road structure is studied for Tangshan including Fengnan district. And according to the analysis results, some feasible suggestions are given. The results of this study may provide reference and guidance for researchers on Tangshan bus route planning and design.
\end{abstract}

Keywords: Tangshan bus network; Space-P network; Space-L network; spatial road structure

\section{Introduction}

Recently, the studies of bus traffic networks based on complex network theory have attracted extensive research interests. Generally, two different models of urban public bus network, namely bus line Space-L network model and bus transfer Space-P network model, are widely used. In bus line Space-L network model, a node corresponds to a bus stop, and an edge represents a link between two adjacent bus stops on the same line. The weight on the line is the number of bus routes between two adjacent bus stops [1-2]. While in bus transfer Space-P network model a node is also a bus stop, but the edges are formed by the connects between all pairs of bus stops in the same bus route [3]. Unlike the line Space-L networks model, this method is mainly used to measure whether two stops are accessible by the same bus route, thus it is a completely connected graph and an undirected weighted network [4].

Line Space-L network model and transfer Space-P network model are firstly used in static characteristic analysis for railway in 2003. Because of the similarity between railway network and urban public transport network, this method was widely used in topologic properties for urban public bus network at home and abroad [5]. The model is used for study traffic network in, for example, Curitiba in Brazilian [3], Debrecen, Szeged, etc in Hungarian [6], London, Manchester, etc in Great Britain [7], Mumbai, Delhi, etc in India [8], Opole, Kielce, etc in Poland [9].

The case study of cities in China are usually selected to large cities, such as Shanghai [10], Beijing [2, 11], Shenzhen [12], Xi'an [13], Chengdu [14], Chongqing [15] and so on. Because these large cities contain many bus

ISSN: 0010-8189

(C) CONVERTER 2020

www.converter-magazine.info 
stops to form a large scale complex network. And researchers' results can obviously prove small-world properties and scale-free laws in urban public bus networks.

In recent years, researchers have applied spatial information to the study of public transport network, and given some reasonable suggestions for optimizing public transport network according to economic development, population density, topographic features, and so on. There are some successful cases in China, such as Fuzhou and Huangshi [16-17].

Tangshan is a typical city with bus as the main public traffic transportation method, without subway and light rail. Therefore, it is particularly important for local residents to have an optimized public transport. This paper also mainly uses complex network theory and spatial road structure to analyze the topologic properties of Tangshan bus network, and gives some reasonable expiations and feasible suggestions for Tangshan bus system according to bus planning, city development, population density and so on.

\section{Status on Tangshan Bus Network}

Tangshan has 7 municipal districts, 3 county-level cities and 4 counties. Because of districts' development, Tangshan bus network only links six municipal districts, which are Lunan, Lubei, Kaiping, Guye, Fengrun and Fengnan. However, Caofeidian district, 3 county-level cities and 4 counties are not connected to the Tangshan bus network. The central area of Tangshan is Lunan and Lubei District.

Until the end of 2020, there are 144 bus lines in Tangshan City, with a total length of $2233.4 \mathrm{~km}$, annual passenger volume of 280 million citizen times, annual driving mileage of 92.08 million km, daily operation of 18000 trains, and 17 bus Parks. The locations of bus parks in Tangshan are shown in Figure 1, and the corresponding bus park are named in Table 1. The bus network in the central area of Tangshan as the backbone and the surrounding regional network as the supplement, it connects the central area and rural areas and covers the urban public transport network of the whole Tangshan city.

ISSN: 0010-8189

(C) CONVERTER 2020

www.converter-magazine.info 


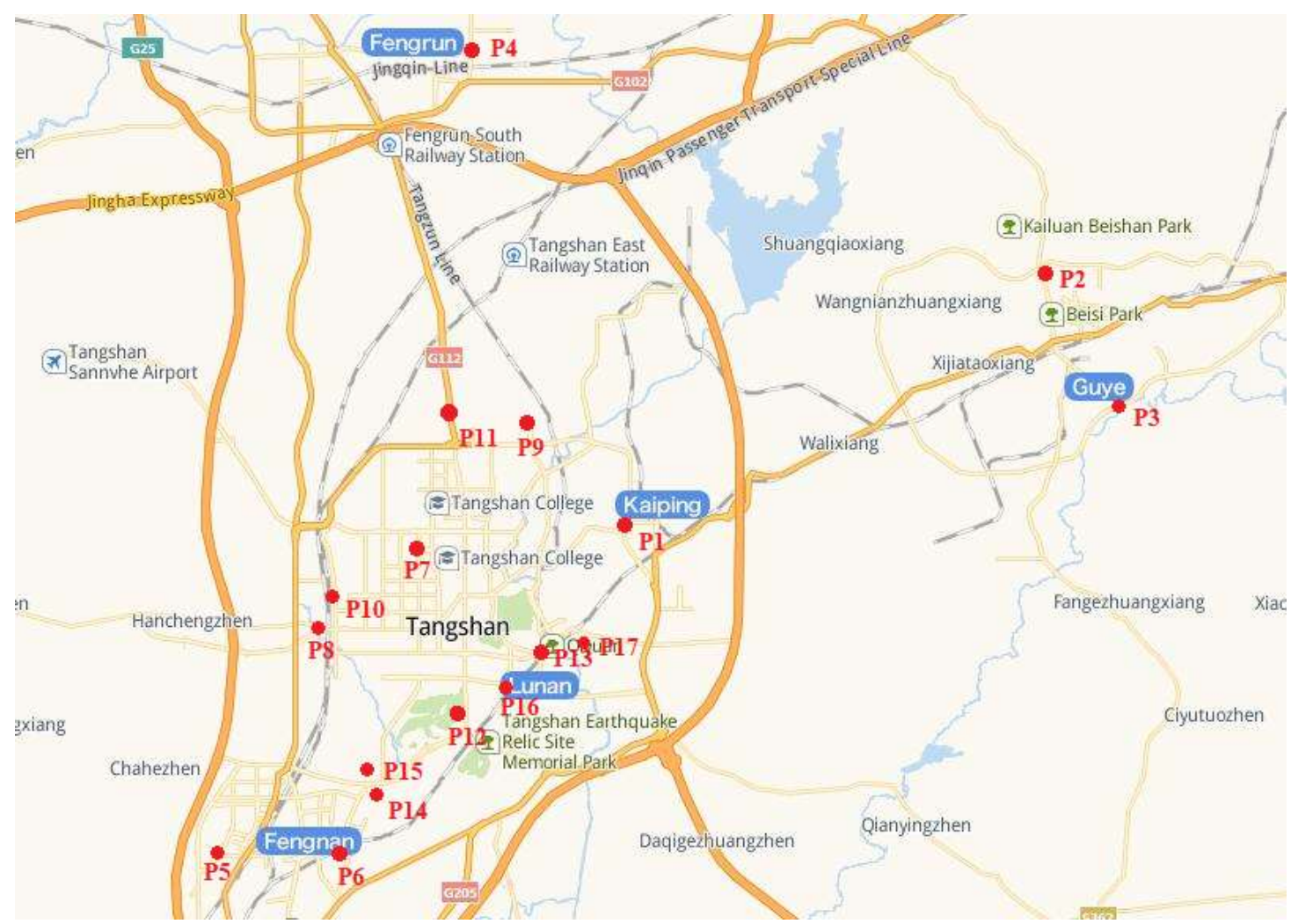

Fig 1: The location of bus parks in Tangshan

Table 1 Symbol and bus parks marked in Figure 1

\begin{tabular}{|c|c|}
\hline Symbol & Bus park name \\
\hline P1 & Phoenix Flower Yard \\
\hline P2 & GuYe North Ring Bus Park \\
\hline P3 & LinXi Bus Park \\
\hline P4 & FengRun District Bus Park \\
\hline P5 & Canal Chinatown Scenic Resort Bus Park \\
\hline P6 & FengNan Bus Station \\
\hline P7 & LanTian Estate Bus Park \\
\hline P8 & TangShan Station \\
\hline P9 & Dingjiatun Bus Park \\
\hline P10 & BeiJiao Bus Park \\
\hline P11 & FengJing Bus Park \\
\hline P12 & QiXin Bus Park \\
\hline P13 & NanHu Bus Park \\
\hline P14 & WangHeZhuang Bus Park \\
\hline P15 & TangShan North Station \\
\hline P16 & Bus East Station \\
\hline P17
\end{tabular}

\section{Abstraction for Tangshan Bus Network}

In this paper, the database collation are used each bus up lines, and different branch lines and express lines are regarded as different lines. The same station name is treated as the same bus stop, regardless the difference of bus stop location. The data used in this paper comes from Tangshan public transport official website, and the time is up to the end of 2020. The weight of Tangshan bus network is not considered the influence of line transportation

ISSN: 0010-8189

(C) CONVERTER 2020

www.converter-magazine.info 
capacity, departure frequency, passenger carrying situation, ticket price, distance between adjacent bus stops, platform design and so on.

\section{Tangshan Bus Line Space-L Network}

A bus stop is a node in the Tangshan bus line Space-L network, and an edge connects two adjacent bus stops on the same line. The weight of an edge represents the total number of lines crossing the two adjacent bus stops [4]. According to above modeling method, Tangshan bus line Space-L network is produced as shown in Figure 2. There are 1130 nodes and 2658 edges. Tangshan bus stops is distributed in six districts, namely, Lubei, Lunan, Fengrun, Fengnan, Kaiping and Guye. We are marked these districts with six colors in Figure 2 in order to distinguish different districts.

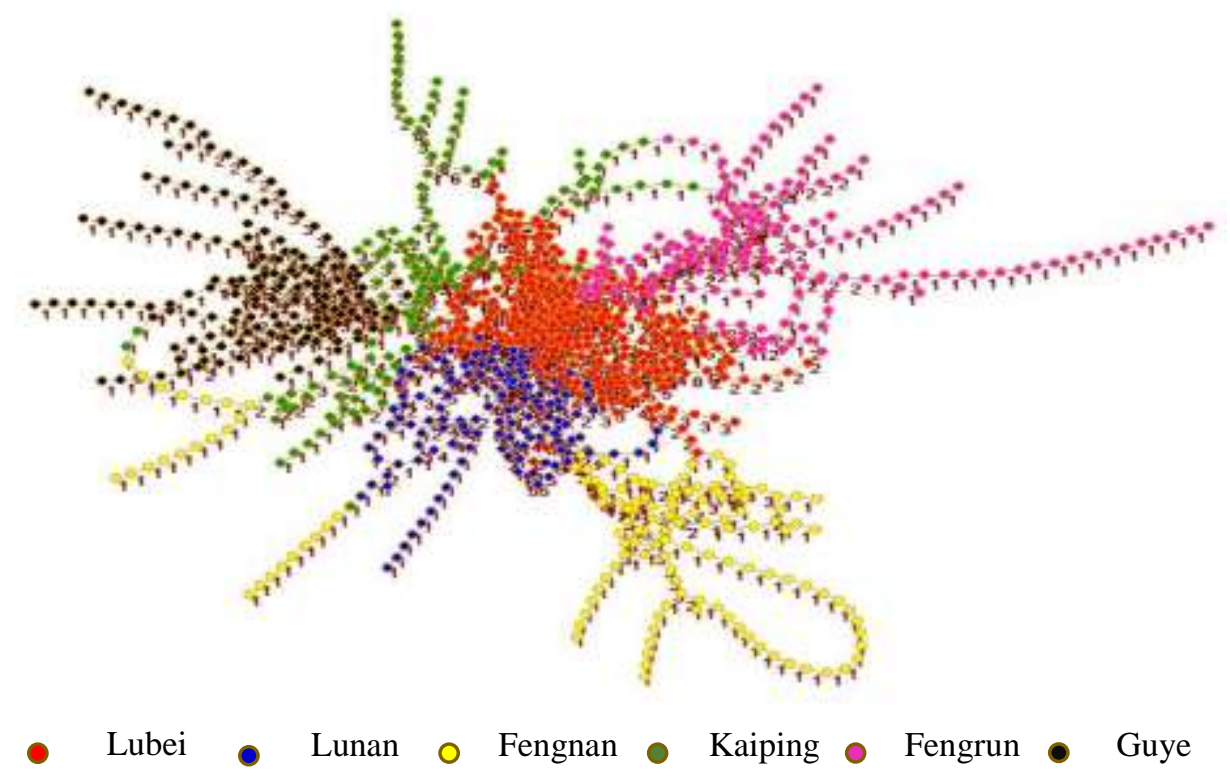

Fig.2: Tangshan bus line Space-L network by Pajek

The total number of bus stops in Lubei, Lunan, Kaiping, Fengnan, Fengrun and Guye districts are 330, 155, 143, 138, 181 and 183 in order. We can also see that the total number of bus stops in Lubei District is much higher than that of other districts. This also more or less reflects that the comprehensive development in Lubei district of Tangshan is far better than that of other districts, such as traffic and people.

\section{Topologic Properties of Tangshan Bus Line Space-L Network}

\subsection{Node Degree and Degree Distribution}

A node's degree is the number of other nodes connected to it, however node distribution is the probability distribution function of node degree, defined as:

$$
P(k)=\frac{n(k)}{\sum_{j=1}^{\infty} n(j)}
$$

Where, $\mathrm{n}(\mathrm{k})$ represents the number of nodes with degree $\mathrm{k}$. The weight of the edge is ignored and only consider the connection itself. The node degree $\mathrm{k} \in[1,11]$ is obtained by statistics. The average node degree $\langle\mathrm{k}\rangle \approx 2.70$, which shows that one bus stop average directly connected with three bus stops. The statistics of the node degree for Tangshan bus line Space-L network is shown in Table 2.

ISSN: 0010-8189

(C) CONVERTER 2020

www.converter-magazine.info 
Table 2 Statistics of the node degree for Tangshan bus line Space-L network

\begin{tabular}{|c|c|c|c|c|c|c|c|c|c|c|c|}
\hline Node Degree & 1 & 2 & 3 & 4 & 5 & 6 & 7 & 8 & 9 & 10 & 11 \\
\hline Numbers of Node & 50 & 636 & 207 & 146 & 52 & 25 & 8 & 3 & 1 & 0 & 2 \\
\hline Proportion & $4.42 \%$ & $56.28 \%$ & $18.32 \%$ & $12.92 \%$ & $4.60 \%$ & $2.21 \%$ & $0.71 \%$ & $0.27 \%$ & $0.09 \%$ & $0 \%$ & $0.18 \%$ \\
\hline
\end{tabular}

The max node degree is 11 , which responds to Pelagic shopping mall and department store. Since the earthquake, the department store has been the center of Tangshan. Now Tangshan has developed into three major centers: the west square of Tangshan station, Tangshan phoenix new area and Tangshan Pelagic shopping mall. It can be seen that the development of Tangshan Pelagic shopping mall is the largest among the three. 56.28\% of the bus stop' degree is 2 and is not in the central area of Tangshan. For example Jiaoda stop in bus line 1, which is the longest line running in Tangshan and was very busy line thirty years ago, but now with most of bus stop' degree without originating stop and terminal stop in bus line 1 being 2, because with the change of development and construction in Tangshan, now no people has lived there.

There are 50 bus stops with node degree value of 1 . And the most bus stops which node degree is 1 are terminal stop away from the Tangshan center. All above shows that Tangshan bus network covers a wide range of bus stops, but there are not enough lines connect all bus stops. There are no bus stop' degree is 10 . The stops with node degree less than or equal to 3 account for $79.02 \%$ of the total number. It shows that the node degree distribution is extremely uneven, most of the node degrees are relatively small, and a few nodes play an important role in connection.

\subsection{Node Strength}

Node strength is defined as:

$$
s_{i}=\sum_{j \in N_{i}} w_{i j}
$$

Node strength distribution $\mathrm{P}(\mathrm{s})$ is defined as:

$$
P(s)=\frac{s_{i}}{N}
$$

Here, $\mathrm{N}$ is the sum of all nodes strength.

The node strength is the sum of the weights on the connected edges of the nodes, which indicates the total number of bus lines that passes through the bus stop. The larger the node strength distribution is, the higher the actual traffic density of the bus stop is, and the stronger the carrying and transportation capacity are, which corresponding to some places where residents flow intensively and centralized transfer in the actual bus network. Tangshan bus network node strength distribution pie chart is shown in Figure 3 . The node strength $s \in[1,44]$ is obtained by statistics. The average node strength $\langle s\rangle \approx 5.95$, which shows that one bus stop average directly pass through with 6 bus lines. From the node strength analysis, we can draw the following conclusions.

ISSN: 0010-8189

C C CONVERTER 2020

www.converter-magazine.info 


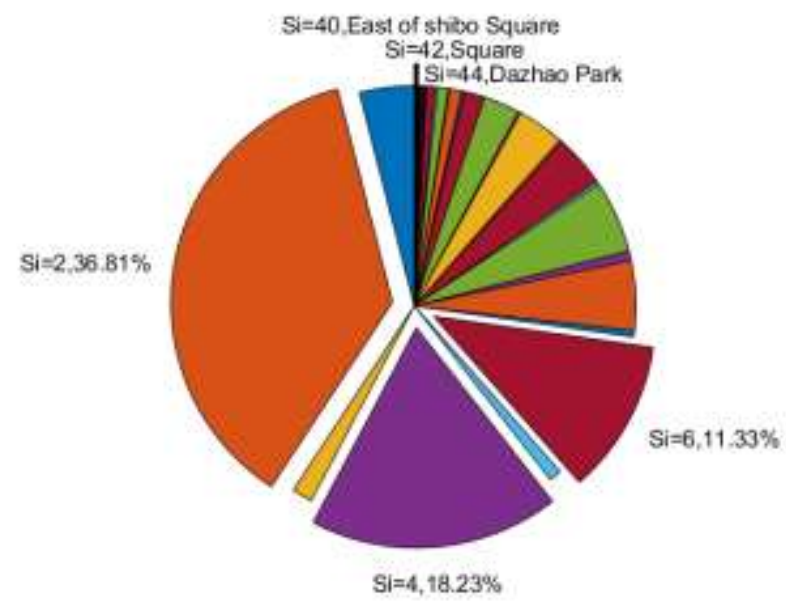

Fig.3: Node strength distribution pie chart in Tangshan bus line Space-L network

(1) The top 3 node strength are 44, 42 and 40, which respectively correspond to bus stops are Dazhao park, square and east of shibo square. There are located in the central area of Tangshan, and pass by with the most bus lines. (2) The min node strength is 1 , which correspond to terminal stops, and only one line passes through the stop. (3) From the node strength distribution, the count of bus stops with node strength is 2 are 416, accounting for $36.81 \%$ of the total, and the largest proportion of all the node strengths. It indicates that most of the bus stops belongs to only one bus line, but this kind of node also has important significance for improving coverage of Tangshan bus network, and increasing travel convenience of citizens. (4) The number of bus stops with node strength is 4 are 206, accounting for $18.23 \%$ of the total, it indicates that $18.23 \%$ of the bus stops have 2 bus lines passing through. (5) While the number of bus stops with node strength is 6 are 128, accounting for $11.33 \%$ of the total, it indicates that $11.33 \%$ of the bus stops have 3 bus lines passing through.

Conclusion (3) (4) (5) shows that the bus stops with the node strength are 2, 4, 6, the corresponding strength distribution are $36.81 \%, 18.23 \%$ and $11.33 \%$ respectively, a total of $66.37 \%$, and the strength of the average $\langle\mathrm{s}\rangle$ is 5.95. It proves once again that a small number of bus stops in Tangshan bus network are important bus stops and play an important role as transportation hubs due to the large number of bus lines.

\subsection{Bearing Pressure}

The section where the station is located in actual bus network often sees various traffic problems due to the imbalance of passenger flow and bus network accessibility, and the spatial road network cannot be connected freely in the actual planning and management of traffic problems. It is often expensive to establish interconnections between two bus stops, and the spatial road network space is limited. Therefore, it is an effective method to save costs and improve the transport efficiency of bus network to investigate the bearing pressure of each bus stop in the limited space of the spatial road network and focus on and optimize the bus stops with high bearing pressure as the key nodes.

Considering the influence of spatial road network complexity on bus network, the ratio of node strength to node degree can be used to show the bearing pressure of spatial road network on bus line in bus network. The complex bus network is based on the spatial road network, and the pressure bearing analysis reflects the restrictions of complex correlation between the bus network and spatial road network. Bearing pressure is defined as:

$$
C C_{i}=\frac{s_{i}}{k_{i}}
$$

Here, $s_{i}$ is the node strength of bus stop $i$, while $k_{i}$ is the degree of bus stop $i$. According to statistics, the node bearing pressure $\mathrm{CC} \in[1,8]$ and the average bearing pressure $\langle C C\rangle=2.01$. The scatter diagram of the node bearing pressure in Tangshan bus line Space- $\mathrm{L}$ network is shown in Figure 4. The maximum bearing pressure is 8, and the corresponding bus stops are the district committee and district government of Lubei and the south of Jianshe road. The number of bus stops with node bearing pressure is 1 are 484 , accounting for $42.79 \%$ of the total.

ISSN: 0010-8189

(C) CONVERTER 2020

www.converter-magazine.info 


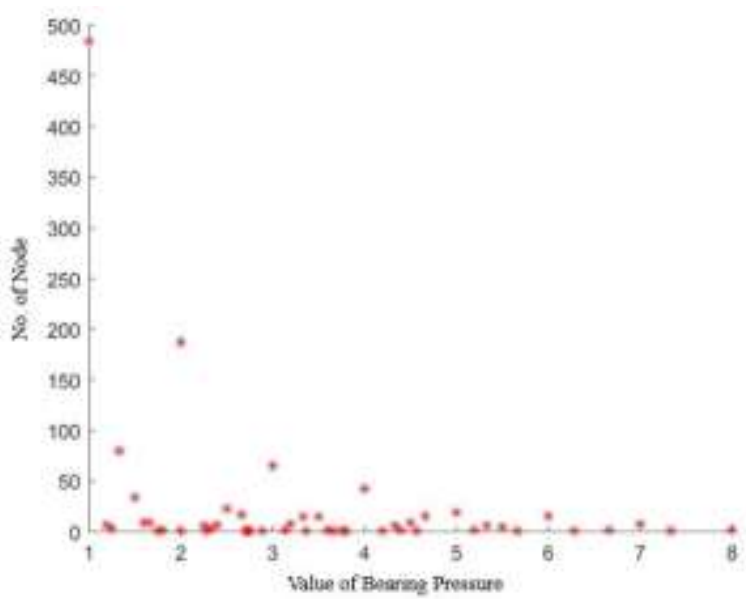

Fig.4: The scatter diagram of the node bearing pressure in Tangshan bus line Space-L network

Table 3 shows the top 11 bus stops with the highest bearing pressure. Analysis of these bus stops location in the road network space can be found, these bus stops are in the central area of Tangshan, mainly concentrated in the administrative institutions and residential area. Therefore, it often shows a large bus demand, and is easy to generate alternate problems in road network bus stop.

Table 3 Top 11 bus stops with the highest bearing pressure in Tangshan bus line Space-L network

\begin{tabular}{|c|c|c|}
\hline Bus stops No. & Bus stop name & Bearing pressure \\
\hline 34 & the district committee and district government of Lubei & 8 \\
\hline 212 & South of Jianshe road & 8 \\
\hline 37 & Shuiji & 7.33 \\
\hline 116 & Hehuakeng & 7 \\
\hline 117 & Aiguoli & 7 \\
\hline 131 & Optimus & 7 \\
\hline 167 & Huamei porcelain factory & 7 \\
\hline 168 & Tangshan No.1 porcelain factory & 7 \\
\hline 196 & Liuhexuanfu & 7 \\
\hline 336 & Ruisa college No.1 & 7 \\
\hline 456 & Semi steel & 7 \\
\hline
\end{tabular}

\subsection{Clustering Coefficient}

Clustering coefficient analysis can identify the dense and sparse regions in the network, reflect the community structure adjacent nodes, and thus find the global distribution pattern and the correlation among nodes. Here the clustering coefficient of node $i$ is calculated as:

$$
C_{i}=\frac{2 E_{i}}{k_{i}\left(k_{i}-1\right)}
$$

Where, E(i) represents the ratio between the actual number of edges. And the clustering coefficient $\mathrm{C}$ of Tangshan bus line Space-L network is calculated as the average clustering coefficient of all nodes $i$.

$$
C=\frac{1}{N} \sum C_{i}
$$

The clustering coefficient $\mathrm{C}$ is equal to 0.0786 . The clustering coefficient is relatively small, which is not convenient to transfer for citizens, and the Tangshan bus network is relatively sparse. The small clustering coefficient is related to the following factors: (1) The count of bus stops with clustering coefficient is 0 are 827 . (2) There are 50 bus stops have node degree 1, so they have no clustering coefficient. (3) The maximum clustering coefficient is 0.6667 , with a total of 6 bus stops. There are south of Guangming court, No.21 court, north China university of science and technology affiliated hospital, Tangshan Hongci healthcare group, Gao village garage,

ISSN: 0010-8189

(C) CONVERTER 2020

www.converter-magazine.info 
west of Guye station, and all of them are located in large communities, hospitals and train stations. (4) The count of bus stops with clustering coefficient is 1 are 24 .

\section{Tangshan Bus Transfer Space-P Network}

A bus stop is a node in the Tangshan bus transfer Space-P network, and an edge connect two arbitrary bus stops on the same line. There are 1130 nodes and 2262 edges. Tangshan bus transfer Space-P network is shown in Figure 6, and it shows the geographical distribution of bus stops, such as bus stops in Lunan and Lubei district are still in the central area of Tangshan, bus stops in Guye, Fengrun and Fengnan district are distributed centrally in its district, bus stops in Kaiping district are located in between Guye District and the central area of Tangshan.

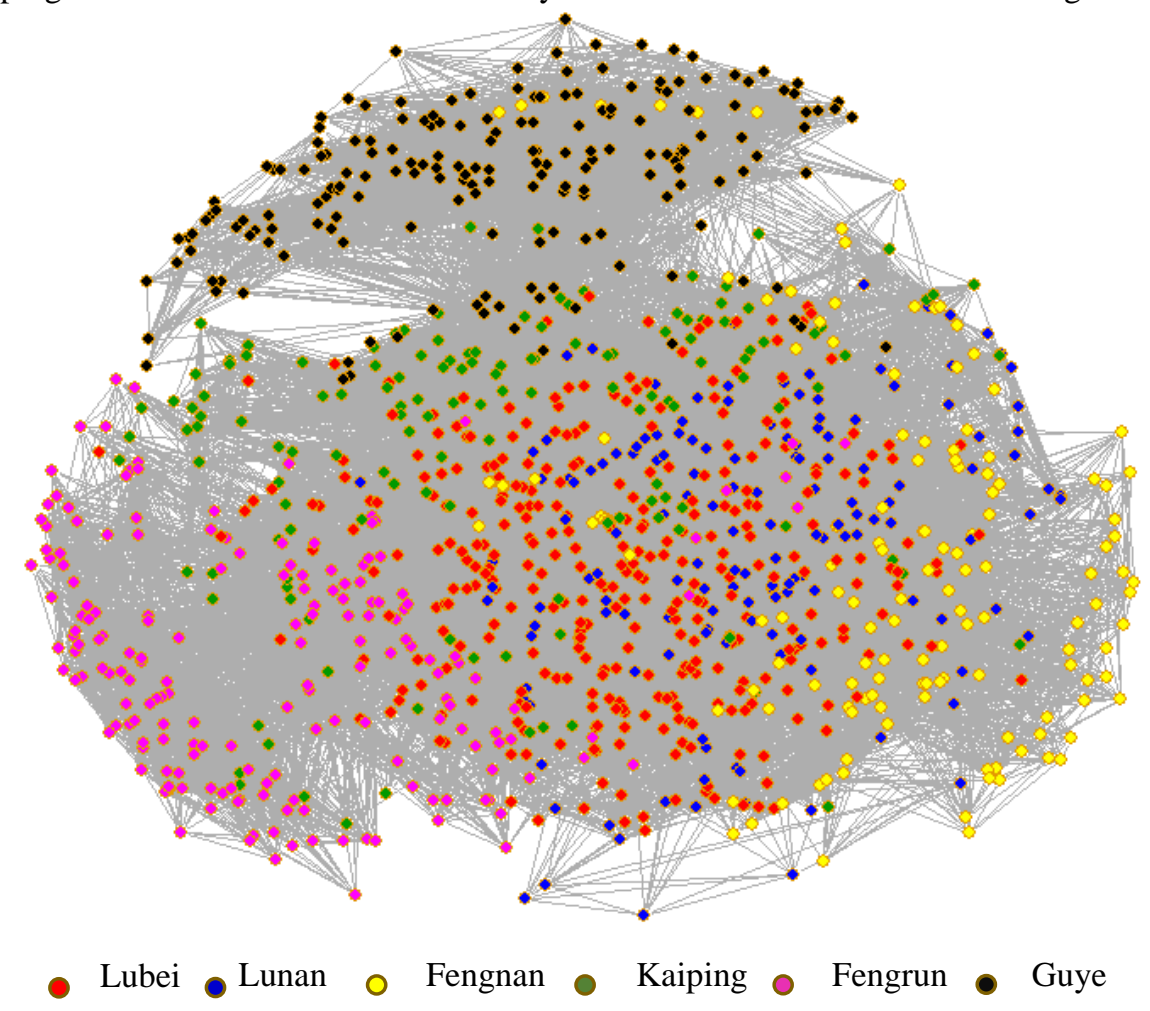

Fig. 5: Tangshan bus transfer Space-P network by Pajek

\section{Topologic Properties of Tangshan Bus Transfer Space-P Network}

The two typical parameters of bus transfer Space-P network are the degree of nodes and the distance between nodes. Here we also calculated closeness centrality and betweenness centrality.

\subsection{Node Degree and Degree Distribution}

The node degree represents the number of bus stops that can be directly reached from one bus stop without changing bus lines in bus transfer Space-P network [10]. The degree $k_{i}$ of the bus stop $i$ is expressed as:

$$
k_{i}=\sum_{j=1}^{N} e_{i j}
$$

Where $e_{i j}$ represents the edge between node $i$ and node $j$. The degree distribution $\mathrm{p}(\mathrm{k})$ refers to the probability that a node is arbitrarily selected in the bus transfer Space-P network and its degree value is $k$. The expression is as follows:

$$
p(k)=\frac{n_{k}}{N}
$$

Where $n_{k}$ is the number of bus stops with node degree $k$, and $N$ is the total number of bus stops.

ISSN: 0010-8189

(C) CONVERTER 2020

www.converter-magazine.info 
It can be conducted that node degree $k \in[7,318]$, and average node degree $\langle\mathrm{k}\rangle \approx 61$ by statistics. It means that there is no need to transfer from one bus stop to the other 61 bus stops on average.

Table 4 shows the top 10 bus stops with the highest node degree in Tangshan bus transfer Space-P network. And these bus stops all located in the central area of Tangshan, namely Lunan and Lubei district.

Table 4 Top 10 bus stops with the highest node degree in Tangshan bus Space-P network

\begin{tabular}{|c|c|c|c|}
\hline No. & Degree value & Bus stop name & Proportion \\
\hline 1 & 318 & Dazhao Park & $0.09 \%$ \\
\hline 2 & 310 & Tangshan Station & $0.09 \%$ \\
\hline 3 & 308 & Square & $0.09 \%$ \\
\hline 4 & 305 & Pelagic Shopping Mall & $0.09 \%$ \\
\hline 5 & 300 & East of Shibo Square & $0.09 \%$ \\
\hline 6 & 281 & Mining Bureau & $0.09 \%$ \\
\hline 7 & 271 & The District Committee and District Government of Lubei / & $0.18 \%$ \\
& & Jianguo Road & \\
\hline 8 & 268 & Department Store & $0.09 \%$ \\
\hline 9 & 252 & Fengcheng International Trade Aegean & $0.09 \%$ \\
\hline 10 & 247 & QiXin Bus Park & $0.09 \%$ \\
\hline
\end{tabular}

Table 5 shows the last 5 bus stops with the lowest node degree in Tangshan bus Space-P network. And the most of these bus stops not located in the central area of Tangshan, it is verified that again Tangshan bus network covers a wide range of bus stops, but there are not many lines between them.

Table 5 The last 5 bus stops with the lowest node degree in Tangshan bus transfer Space-P network

\begin{tabular}{|c|c|c|c|c|c|}
\hline Degree & Bus Stop Name & District & Line & $\begin{array}{c}\text { Total } \\
\text { Number of } \\
\text { Bus Stops }\end{array}$ & Proportion \\
\hline 7 & $\begin{array}{l}\text { Tangshan Yate Special Vehicle Co. Ltd /South } \\
\text { of Zheng Village/ North of Zheng Village / } \\
\text { South of Linage Village / Linage Village }\end{array}$ & Kaiqing & No.95 & 8 & $0.44 \%$ \\
\hline 10 & $\begin{array}{l}\text { Seven Four Building/Damalu Police Office/ } \\
\text { ZhaoGeZhuang Mining Corporation / } \\
\text { ZhaoGeZhuang Hospital / Beishan Park / } \\
\text { Changshan Worker-house / Sanyou } \\
\text { community/ Tangshan Sanyou Mine Co., Ltd. }\end{array}$ & Guyu & No.212 & 11 & $0.71 \%$ \\
\hline \multirow{3}{*}{11} & $\begin{array}{l}\text { Dongjiao Sewage Treatment Plant /East of } \\
\text { Yuehe Village / Beitatou Village }\end{array}$ & Kaiping & No.53 & 12 & \multirow{3}{*}{$1.06 \%$} \\
\hline & $\begin{array}{l}\text { East of Hehuakeng / Shengli Oleochemicals } \\
\text { Plant / North Street of Nvzhi Village / North } \\
\text { Street of Nvzhi Village /Zhaotian Village }\end{array}$ & Lunan & No.76 & 12 & \\
\hline & $\begin{array}{l}\text { No.3 Village /Dongxin Building / North Plant / } \\
\text { Shuiyu Village Committee }\end{array}$ & Guye & No.214 & 12 & \\
\hline 12 & $\begin{array}{l}\text { East of Zhouzhao Village / Zhouzhao Village / } \\
\text { New House / Tangshan Yulin High School }\end{array}$ & Kaiping & No.57 & 3 & $0.35 \%$ \\
\hline \multirow{3}{*}{13} & East of Zhengyuan Street & Fengnan & No.92 & \multirow{3}{*}{14} & \multirow{3}{*}{$0.27 \%$} \\
\hline & Zhen Village & Lubei & No.K3 & & \\
\hline & Wang Village & Fengrun & No.K3 & & \\
\hline
\end{tabular}

\subsection{Distance between Nodes}

The distance between nodes can be interpreted as the number of bus lines passengers need to take from one bus stop to another, that is, the number of transfers +1 . The average value of the shortest distance between any two accessible bus stops in Tangshan bus transfer Space-P network is 2.83, that is, citizens in Tangshan need to change

ISSN: 0010-8189

(C) CONVERTER 2020

www.converter-magazine.info 
buses 1.83 times per trip on average. Citizens in Lunan and Lubei Districts of Tangshan basically can be reached directly without transfer, but if you consider the whole 6 districts in Tangshan, they often need to transfer. This is because citizens travel cross-district bus stops, such as Fengrun, Fengnan, Guye and Kaiping district, need to transfer to the central area of Tangshan.

\subsection{Closeness Centrality}

Closeness centrality is used to measure the distance between a node and other nodes in the network, indicating how easy it is for passengers to transfer to other bus stops at the current bus stop $i$. The larger the value $c c_{i}$ is, the lower the transfer difficulty is. The normalized closeness centrality is expressed as follows:

$$
c c_{i}=\frac{N-1}{\sum_{j=1}^{N} d_{i j}}
$$

Where, $i$ is the central node, $j$ is another node $(\mathrm{i} \neq \mathrm{j})$, and $d_{i j}$ is the shortest distance between the two nodes. Bus stops with high closeness centrality should be located in the center of Tangshan bus transfer Space-P network because they have the largest number of other bus stops clustered around them.

The distribution of closeness centrality in Tangshan bus transfer Space-P network is shown in Figure 6. The maximum value of closeness centrality is 0.561 , the minimum value is 0.305 , and the average value is 0.398 , and the distribution is mainly in the range of $0.3 \sim 0.55$. The higher the average value of closeness centrality is, the less difficult it is to transfer from one stop to another in the bus network.

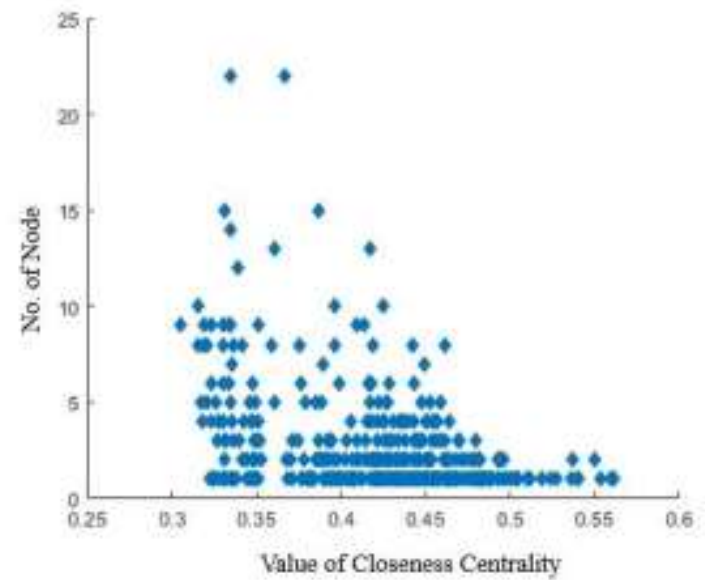

Fig. 6: Closeness centrality distribution of bus stops in Tangshan bus transfer Space-P network

Table 6 shows the top 10 bus stops with the highest closeness centrality. It can be seen that these bus stops are all concentrated in the central area of Tangshan, and $80 \%$ of them also have high degree rank in Tangshan bus transfer Space-P network.

Table 6 Top ten bus stops with highest closeness centrality

\begin{tabular}{|c|c|c|c|c|c|}
\hline No. & $\begin{array}{c}\text { Closeness } \\
\text { centrality }\end{array}$ & Bus stop name & No. & $\begin{array}{c}\text { Closeness } \\
\text { centrality }\end{array}$ & Bus stop name \\
\hline 1 & 0.5611 & Pelagic Shopping Mall & 6 & 0.5397 & Dazhao Park \\
\hline 2 & 0.5597 & Tangshan Station & 7 & 0.5374 & $\begin{array}{c}\text { FengJing Bus Park / Tangshan } \\
\text { mine air shaft }\end{array}$ \\
\hline 3 & 0.5534 & Square & 8 & 0.5363 & East of Shibo Square \\
\hline 4 & 0.5499 & $\begin{array}{c}\text { The District Committee and } \\
\text { District Government of Lubei } \\
\text { / Jianguo Road }\end{array}$ & 9 & 0.5271 & Nanxin Crossing \\
\hline 5 & 0.5401 & Mining Bureau & 10 & 0.5237 & Department Store \\
\hline
\end{tabular}

7.4 Betweenness Centrality

ISSN: 0010-8189

(C) CONVERTER 2020

www.converter-magazine.info 
Betweenness centrality measures the load of nodes in the network. The closer the bus stop is to the center, the more the number of shortest paths passing through the bus stop is, and the greater the congestion of the bus stop and its influence on transfers. The betweenness centrality of the node $i$ is calculated as follows:

$$
b c_{i}=\frac{\sum_{j \neq k} \sigma_{j k}(i)}{\sigma_{j k}}
$$

Where $\sigma_{j k}$ represents the number of shortest paths from the bus stop $j$ to the bus stop $k$, and $\sigma_{j k}(i)$ represents the number of shortest paths from the bus stop $j$ to the bus stop $k$ and passing through the bus stop $i$.

On one hand, betweenness centrality reflects the traffic information of the bus stop, and its analysis results can determine the bus stop with high possibility of congestion. On the other hand, betweenness centrality can reflect the impact on citizens' travel when a bus stop is down.

The top 10 bus stops with highest betweenness centrality is shown in Table 7, that is, the bus stops with a high probability of congestion. It can be seen from Table 7 that these bus stops are scattered in Kaiping, Guye, Lubei and Fengrun districts, and most of these bus stops are located in or near the bus parks as shown in Figure 1. Since the maximum betweenness centrality of Tangshan bus transfer Space-P network is only 0.025, the paralysis of a single bus stop has little impact on citizens' transfer trips. This is because there are many repeated bus stops along the Tangshan bus line and the coverage rate of bus stop is wide. In addition, there are 474 bus stops in Tangshan bus transfer Space-P network with betweenness centrality is 0 , which means that there is no congestion at all. This reduces the average betweenness centrality value of the whole network to only 0.005 , indicating that the overall congestion is relatively light.

Table 7 Top 10 bus stops with highest betweenness centrality

\begin{tabular}{|c|c|c|c|c|c|c|c|}
\hline No. & $\begin{array}{c}\text { Betweenness } \\
\text { centrality }\end{array}$ & Bus stop name & District & No. & $\begin{array}{c}\text { Betweenness } \\
\text { centrality }\end{array}$ & Bus stop name & District \\
\hline 1 & 0.0251 & $\begin{array}{c}\text { GuYe North Ring } \\
\text { Bus Park }\end{array}$ & GuYe & 6 & 0.0095 & $\begin{array}{c}\text { North Shopping } \\
\text { Plaza }\end{array}$ & FengRun \\
\hline 2 & 0.0226 & LinXi Bus Park & GuYe & 7 & 0.0093 & $\begin{array}{c}\text { Phoenix Flower } \\
\text { Yard }\end{array}$ & KaiPing \\
\hline 3 & 0.0120 & Red Star Macalline & KaiPing & 8 & 0.0088 & $\begin{array}{c}\text { Fengrun Li } \\
\text { Village }\end{array}$ & FengRun \\
\hline 4 & 0.0102 & $\begin{array}{c}\text { Jidong Antique } \\
\text { City/Guohua } \\
\text { Technology Group }\end{array}$ & LuBei & 9 & 0.0087 & $\begin{array}{c}\text { Fengrun No.3 } \\
\text { Court }\end{array}$ & FengRun \\
\hline 5 & 0.0096 & $\begin{array}{c}\text { LanTian Estate Bus } \\
\text { Park }\end{array}$ & LuBei & 10 & 0.0075 & $\begin{array}{c}\text { Oriental Garden } \\
\text { Court }\end{array}$ & LuBei \\
\hline
\end{tabular}

\section{Road Structure of Tangshan Bus Network}

The road structure of Tangshan bus network corresponding to Figure 2 is shown in Figure 7.

ISSN: 0010-8189

(C) CONVERTER 2020

www.converter-magazine.info 


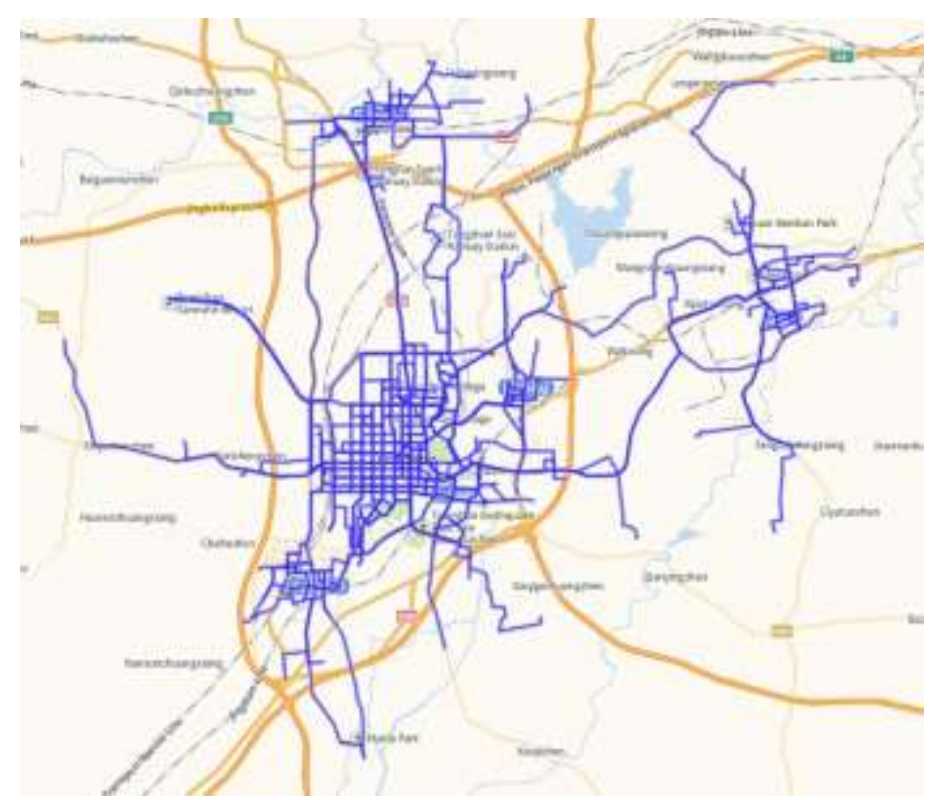

Fig 7: The road structure of Tangshan bus network

It can be seen from Figure 7 that: (1) Lunan and Lubei district constitute the central area of Tangshan, and the composition of bus routes is a typical gridiron road network. This is because Tangshan is a city rebuilt after the earthquake, and the roads are planed into north-south and east-west directions. (2) Kaiping and Fengnan districts, which are closer to the central area of Tangshan, have obviously integrated into the urban bus network due to their geographical advantages. (3) The road structure of Fengnan district is a typical annular radiation type, as shown in Figure 8. The ring line is the special business line of Fengnan district. Moreover, the area of Fengnan district is relatively large, while the area that covers the bus network is not large, which proves that the economic development and population distribution of Fengnan district are mainly concentrated around the canal chinatown scenic resort near the central area of Tangshan. (4) Fengrun and Guye district, which are far away from the central area of Tangshan, both have bus lines connecting between them and the central area of Tangshan, and most of the bus lines are regional buses.

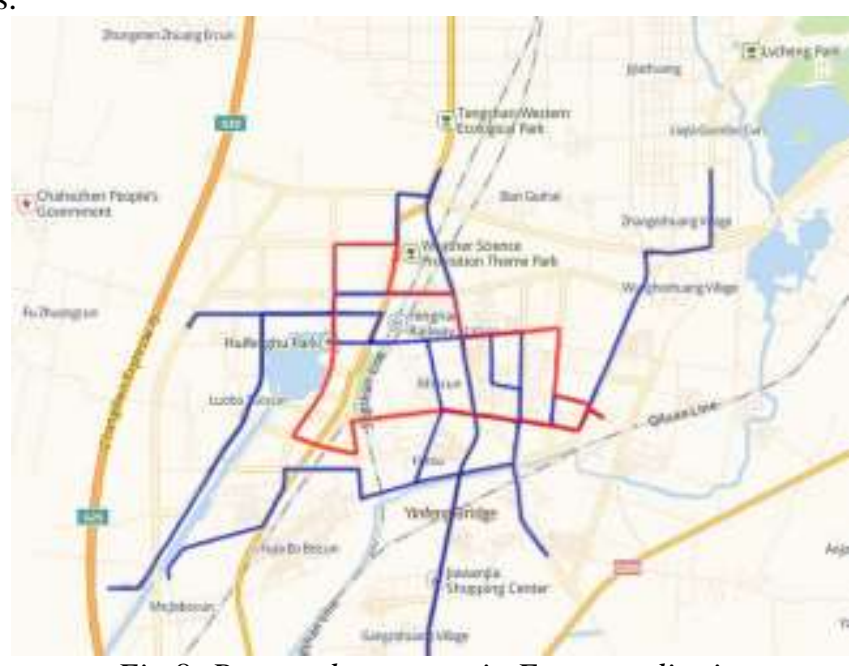

Fig 8: Bus road structure in Fengnan district

\section{Discussions and Suggestions}

The future evolution of Tangshan bus network will affect by the following factors: (1) Lubei district is further divided into Lubei and Gaoxin districts, and the geolocation information in paper comes from Baidu maps and has not been updated. (2) The key newly built areas of Tangshan are Caofeidian new area, Phoenix new area, Nanhu

ISSN: 0010-8189

(C) CONVERTER 2020

www.converter-magazine.info 
ecological city and Airport city. With the further expansion of the establishment of the Tangshan, Tangshan bus network coverage will also expand to these areas. Especially for Caofeidian New area, the government has planned a bus linked between the central of Tangshan and Caofeidian New area. The line is expected to open by the end of 2021. (3) Tourism project of "Tangshan flower sea" is located in Kaiping district, which has attracted a large number of commercial housing developers. Therefore, there will be a new population of permanent residents, and they will have demands for more bus routes. (4) There is a large undeveloped area between Tangshan Lubei and Fengrun District. As the city expands, Tangshan bus lines will be prolonged to the north. (5) Under the guidance of policy, some large industrial enterprises move from the central of Tangshan to coastal area, which will lead to the rapid development of coastal districts, such as Laoting district and Tanggang district. And it will inevitably change the existing structure of Tangshan Public Transport.

The following suggestions are put forward to Tangshan public bus system: (1) Tangshan authority should invest more money to build trolleybus or rail rapid transit lines between districts. At present, there is only one trolleybus line between Caofeidian new area and Tangshan international tourism island. Inter-regional bus lines can connect more districts to the Tangshan bus network to facilitate citizens' travel. (2) Some custom bus lines should be open in Tangshan. For example, custom bus line between Tangshan old town to Tangshan iron and steel Co., Ltd. in Laoting district.

\section{Conclusion}

This paper mainly analyzes Tangshan bus network from two aspects of topological properties and spatial road structure. At present, Tangshan bus network connects 6 districts, namely Lubei, Lunan, Fengrun, Fengnan, Kaiping and Guye. In order to distinguish different districts, the bus stops in these districts are marked with different colors in Figure 2 and Figure 5, respectively. The following conclusions can be drawn from this study.

From node degree, clustering coefficient in Tangshan bus line Space-L network and average distance, closeness centrality in Tangshan transfer Space-P network, we can obviously see that bus stops are dense in Tangshan old town, namely, the central area of Tangshan, where residents do not need to transfer. There are bus lines within each district, namely, reginal buses, such as No.219 line in Guye and No.117 line in Fengnan, and residents no need to transfer within the district. However, residents have to transfer between the four districts of Fengrun, Fengnan, Kaiping and Guye. The reason is related to the distribution of population density in Tangshan. The two districts with the largest population density are still Lubei and Lunan Districts.

From Tangshan bus line space-L network, we can see the development speed of Tangshan in the past 10 years. By the end of 2009, there were 73 bus lines and 412 bus stops in Tangshan [18]. While by the end of 2020, there were 144 bus lines and 1130 bus stops in Tangshan. Its rapid development is due to the fact that in the past, only Lunan and Lubei districts were connected to the Tangshan bus network, but now it includes the adjacent districts of Kaiping, Guye, Fengrun and Fengnan. Tangshan bus network presents an obvious spatial structure of urban clusters.

The research results are helpful to understand the construction mechanism of Tangshan bus network in depth, and will aid the design, optimization and control of such networks, as well as provide services for the further research and application of network behavior.

\section{Acknowledgements}

This work is supported by industry-university-research of cooperative education project for ministry of education in China (Grant: 201902062045, Grant: 201902056008).

\section{References}

[1] Wang Z, Peng Q.Y. Research on Topologic Properties of Chengdu Public Traffic Complex Network. Computer and Communications, 25(2): 39-42, 2007.

[2] Zheng X, Chen J.P., Shao J.L., et al. Analysis on topological properties of Beijing urban public transit based on complex network theory. Acta Phys. Sin. 61(19): 95-105, 2012.

ISSN: 0010-8189

(C) CONVERTER 2020

www.converter-magazine.info 
[3] De Bona A A, Fonseca K V O, Rosa M O, et al. Analysis of Public Bus Transportation of a Brazilian City Based on the Theory of Complex Networks Using the P-Space. Mathematical Problems in Engineering, (pt.6):1-12, 2016.

[4] Yang X.P., Lu S.W., Zhao W.F., et al. Exploring the Characteristics of an Intra-Urban Bus Service Network: A Case Study of Shenzhen, China. International Journal of Geo-Information, 8(11):486, 2019.

[5] Chen G, Wen G.H., Yu W.W. A survey of studies on urban public transportation networks based on complex network. Journal of Nanjing University of Information Science and Technology (Natural Science Edition), 10(4):401-408, 2018.

[6] András London, Andor Háznagy, István Fi, et al. Complex network analysis of public transportation networks: A comprehensive study. 2015 International Conference on Models and Technologies for Intelligent Transportation Systems (MT-ITS): 371-378, 2015.

[7] De Regt R, Von Ferber C, Holovatch Y, et al. Public transportation in UK viewed as a complex network, 2017.

[8] Chatterjee A, Manohar M, Ramadurai G. Statistical Analysis of Bus Networks in India. Plos One, 11(12):e0168478, 2015.

[9] Sienkiewicz J, Hoyst J A. Statistical analysis of 22 public transport networks in Poland. Physical Review E Statistical Nonlinear \& Soft Matter Physics, 72(4 Pt 2):046127, 2005.

[10] Xu Q, Zu Z.H., Xu Z.J., et al. Space P-Based empirical research on public transport complex networks in 330 cities of China. Journal of Transportation Systems Engineering and Information Technology, 13(1):193-198, 2013.

[11] Wang T, Wu L.L. Research on invulnerability of urban transit network based on complex network. Application Research of Computers, 27(11):4084-4086, 2010.

[12] Meng Y.Y., Tian X.L., Li Z.W, et al. Comparison analysis on complex topological network models of urban rail transit: A case study of Shenzhen Metro in China. Physica A: Statical Mechanics and its Applications, 125031, 2020.

[13] Jia G.L., Ma R.G., Hu Z.H. Urban Transit Network Properties Evaluation and Optimization Based on Complex Network Theory. Sustainability, 11, 2019.

[14] Di Z.H., Shuai B, Chong P.Y. Research on Topological Properties of Public Transport Network in Chengdu Based on Complex Network. Journal of Xihua University (Natural Science), 34(6):12-16, 2015.

[15] Li X.H., Guo J.Y., Gao C, et al. Network-based transportation system analysis: A case study in a mountain city. Chaos, Solitons \& Fractals, 107:256-265, 2018.

[16] Jin B, Zhao L, Lin X.L., et al. Analysis and Evaluation of Fuzhou Transit Network Based on Complex Network. Journal of Fujian Normal University (Natural Science Edition), 34(1):17-26.

[17] Xu L.J., Liu X.H. The Characteristic Analysis of Transit Network in Small Cities based on the Complex Network Theory. Journal of Wuhan University of Technology (Transportation Science \& Engineering), 40(6):943-948, 2016.

[18] Li X.M., Cui N.Z., Sun L.P., et al. Research on Static Network Properties of Tangshan Urban Bus System. Journal of Tangshan Trachers College, 32(5):47-49, 2010.

ISSN: 0010-8189 